\title{
Three cases of congenital bilateral ball and socket ankle joints in the same family - a case series
}

\author{
Sandeep Tiwari ${ }^{* 1}$, Prateek Sharma ${ }^{1}$, Parthasarathy Pobbathi ${ }^{2}$, Matthew Morris ${ }^{2}$ \\ ${ }^{1}$ Department of Radiology, Chesterfield Royal Hospital, Chesterfield, Derbyshire, United Kingdom \\ ${ }^{2}$ Department of Trauma and Orthopaedics, Chesterfield Royal Hospital, Chesterfield, Derbyshire, United Kingdom
}

Received: January 13, 2017

Accepted: February 15, $2017 \quad$ Online Published: February 16, 2017

DOI: $10.5430 /$ ijdi.v4n1p34

URL: https://doi.org/10.5430/ijdi.v4n1p34

\begin{abstract}
A 40-year-old lady presented with a 10-year-history of left ankle and foot pain. Clinically the pain was thought to be due to instability of the lateral ligament complex. Bilateral ankle radiographs showed a ball and socket ankle joints. Magnetic Resonance Imaging (MRI) scan of the left ankle in addition showed a chronic tear of the lateral ankle ligaments and subluxation of the peroneal tendons. Subsequently, she underwent an examination under anaesthesia of the left ankle which demonstrated no significant difference in stability between the two sides. Interestingly, because of the daughter's peculiar ankle radiograph appearances, her mother's and son's radiographs of the ankle were reviewed and they also showed similar appearance of bilateral ball and socket joints, favouring congenital aetiology.
\end{abstract}

Key Words: Ball and socket ankle joint, Congenital, Subluxation of peroneal tendons

\section{INTRODUCTION}

Ball and socket ankle joint is a rare abnormality but is important to diagnose. In our case, there was a delay of few months in diagnosing this condition. Therefore, we think that the correct and timely diagnosis of this condition can explain patient's symptoms and also help clinicians to examine the patient for other associated abnormalities and plan further management.

\section{CASE REPORT}

A 40-year-old lady presented with a 10-year-history of left ankle and foot pain, with progressive worsening for the last 3 years. On clinical examination, she had fullness in her left ankle and tenderness over the antero-inferior component of the lateral ligament complex.

Anteroposterior (AP) and lateral radiographs of the left an- kle were performed, which were initially reported as ankle degenerative change with a subchondral cyst within the talar dome (see Figure 1). Magnetic Resonance Imaging (MRI) scan of the left ankle demonstrated partial tear of anterior talo-fibular ligament (ATFL) with tendinopathic change and subluxation of the peroneal tendons (see Figure 2).

On a subsequent review of her imaging in clinicoradiological meeting, it was recognised that she has a ball and socket ankle joint (see Figures 1a, 1b, and 2a) due to the unusual shape of the talus, more rounded in shape. Her right ankle radiographs performed later on, also showed a similar appearance (see Figure 3).

Due to persistent pain she also underwent examination under anaesthesia (EUA) of the left ankle, which did not demonstrate any difference in stability of the left ankle joint as compared to the right side. At this point, she was also offered

\footnotetext{
*Correspondence: Sandeep Tiwari, MD; Email: drsandytiwari@gmail.com; Address: Department of Radiology, Chesterfield Royal Hospital, Chesterfield, S44 5BL, United Kingdom.
} 
surgical option involving peroneal tendon sheath stabilisation the favour of a surgery. and groove deepening procedure. Currently, she has declined the operation and has an open appointment if she decides in
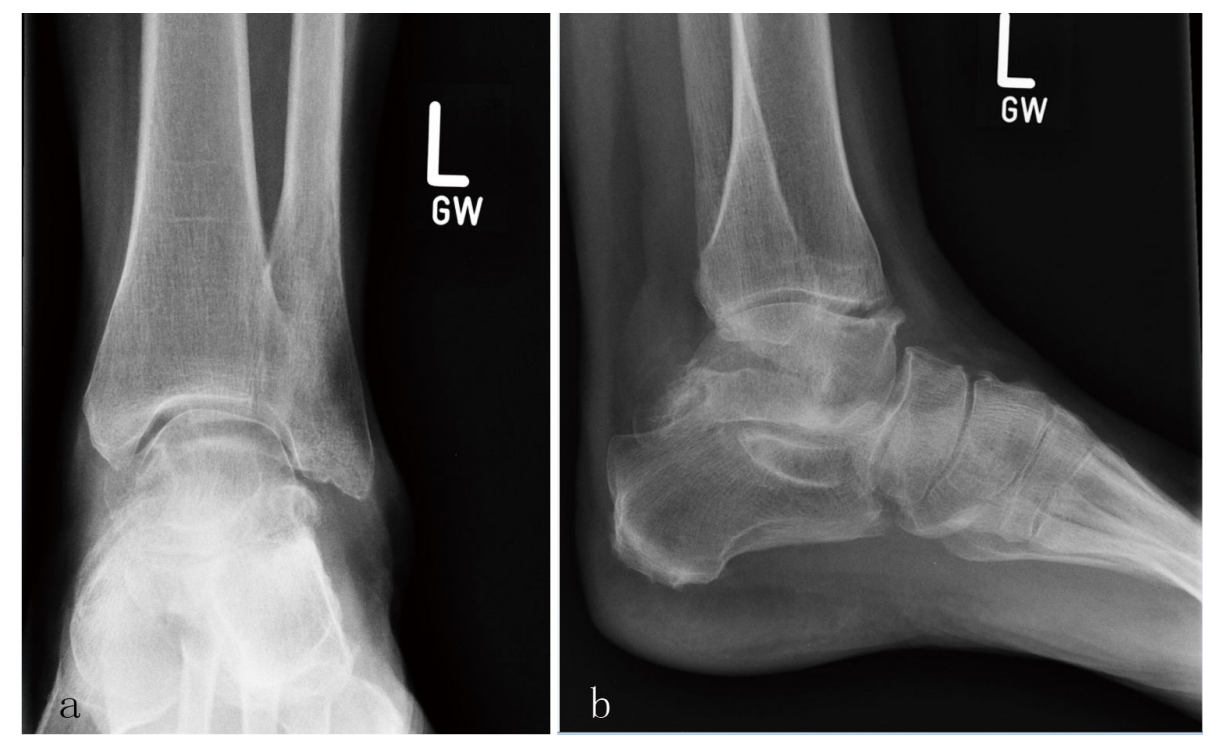

Figure 1. AP and lateral radiograph of the left ankle showing ball and socket ankle joint with a subchondral cyst within the talar dome
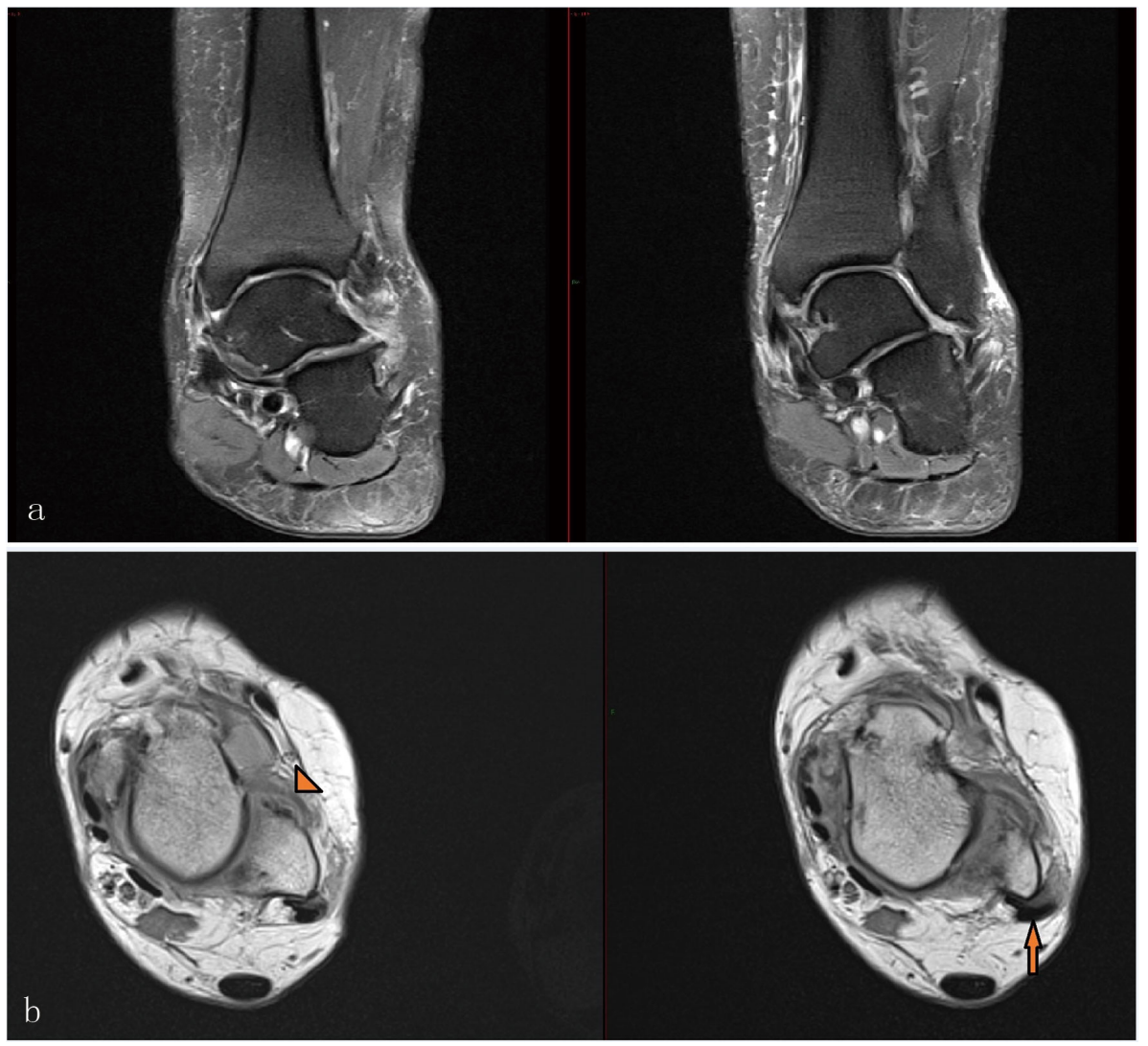

Figure 2. a. Proton density fat saturation (PDFS) coronal view of the left ankle confirmed ball and socket joint; b. Proton density axial view showing thickening and increased signal within ATFL, in keeping with partial tear (arrowhead) with tendinopathic change and subluxation of the peroneal tendons (arrow) 

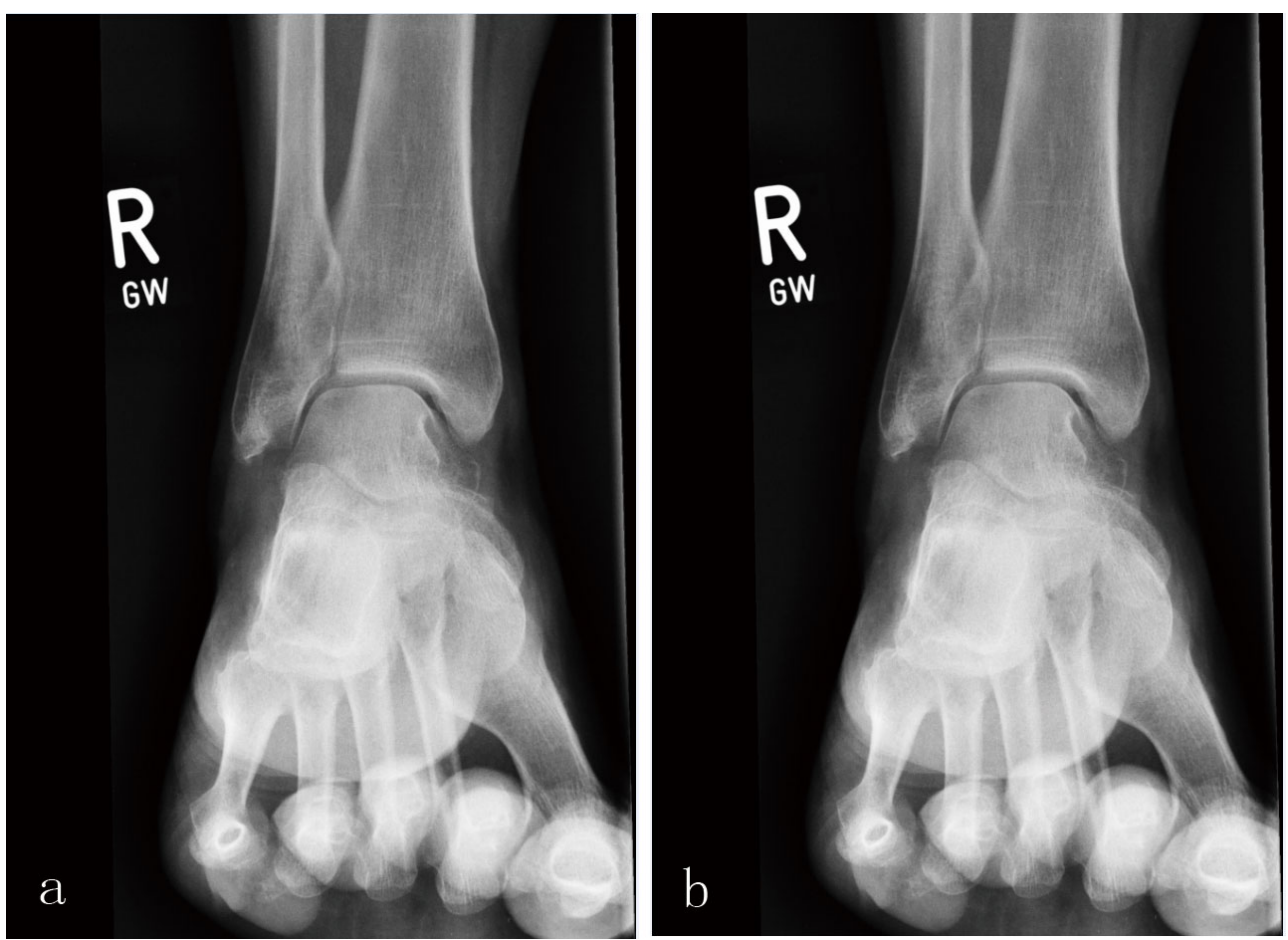

Figure 3. AP and lateral radiographs of the right ankle showing ball and socket ankle joint

In the next clinic review, it was discovered that her mother was also on the waiting list for bilateral ankle fusion due to ankle pain. On review of the radiographs it was noted that she has also got bilateral ball and socket ankle joints (see Figure 4). On direct questioning she also mentioned about a complain of intermittent pain in both the ankles of her 14-year-old son. The patient's son afterwards attended orthopaedic clinic and was also diagnosed to have bilateral ball and socket ankle joints on plain radiographs (see Figure $5)$.

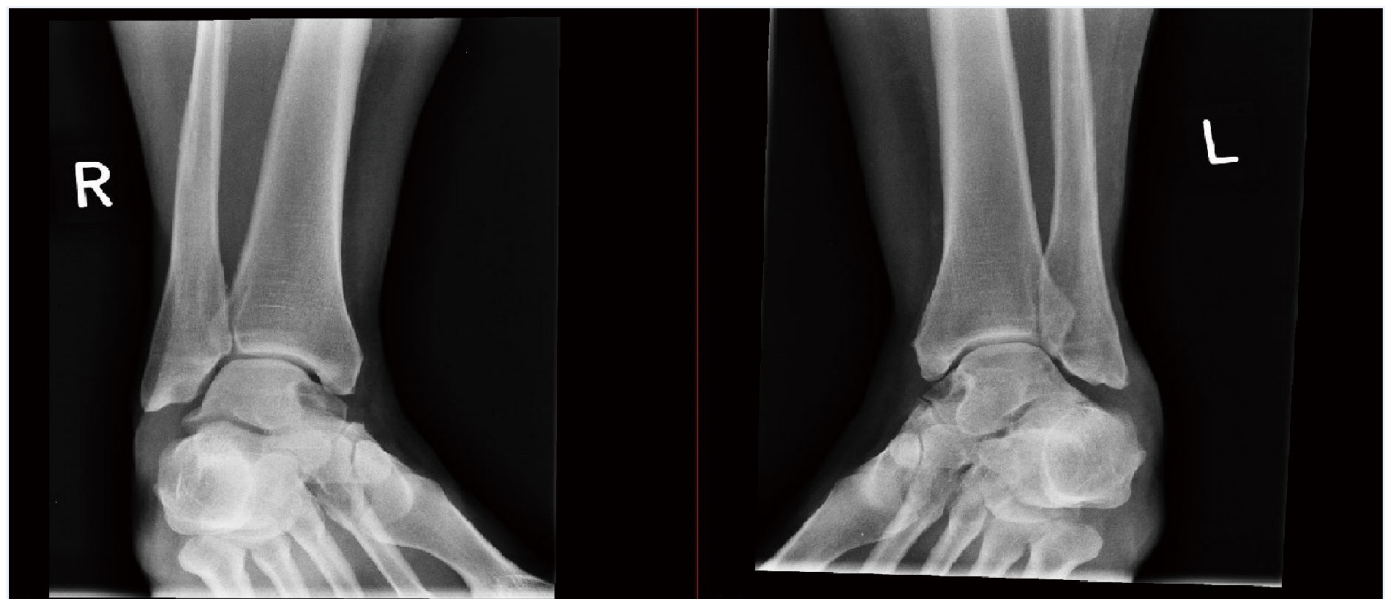

Figure 4. AP view radiographs of both ankles demonstrating bilateral ball and socket joints

\section{Discussion}

Ball and socket ankle joint was first described by Lamb in $1958 .^{[1]}$ Ball and socket ankle joint is a rare deformity characterised by a spherical articulation between the tibia and talus. ${ }^{[1]}$ The talus shows a dome top in both anteroposte- rior and lateral views. ${ }^{[2]}$ Its aetiology has been the subject of controversy with two schools of thought: the congenital abnormal joint theory and the secondary adaptive joint theory. ${ }^{[1]}$ Congenital ball and ankle joint has been associated with other lower limb deformities like inequality of leg 
length, fibular hypoplasia, coalition of the tarsal bones, and ray deficiency. ${ }^{[2-5]}$ It is also associated with laxity of ankle ligaments. ${ }^{[2]}$ In acquired variety, the rounding is not as smooth as in the congenital variety. ${ }^{[2]}$ Ball and socket ankle joint can also be associated with short limb and hypoplastic sustantaculum tali. ${ }^{[6]}$

These patients can develop end stage subtalar and/or ankle joint arthritis. ${ }^{[7]}$

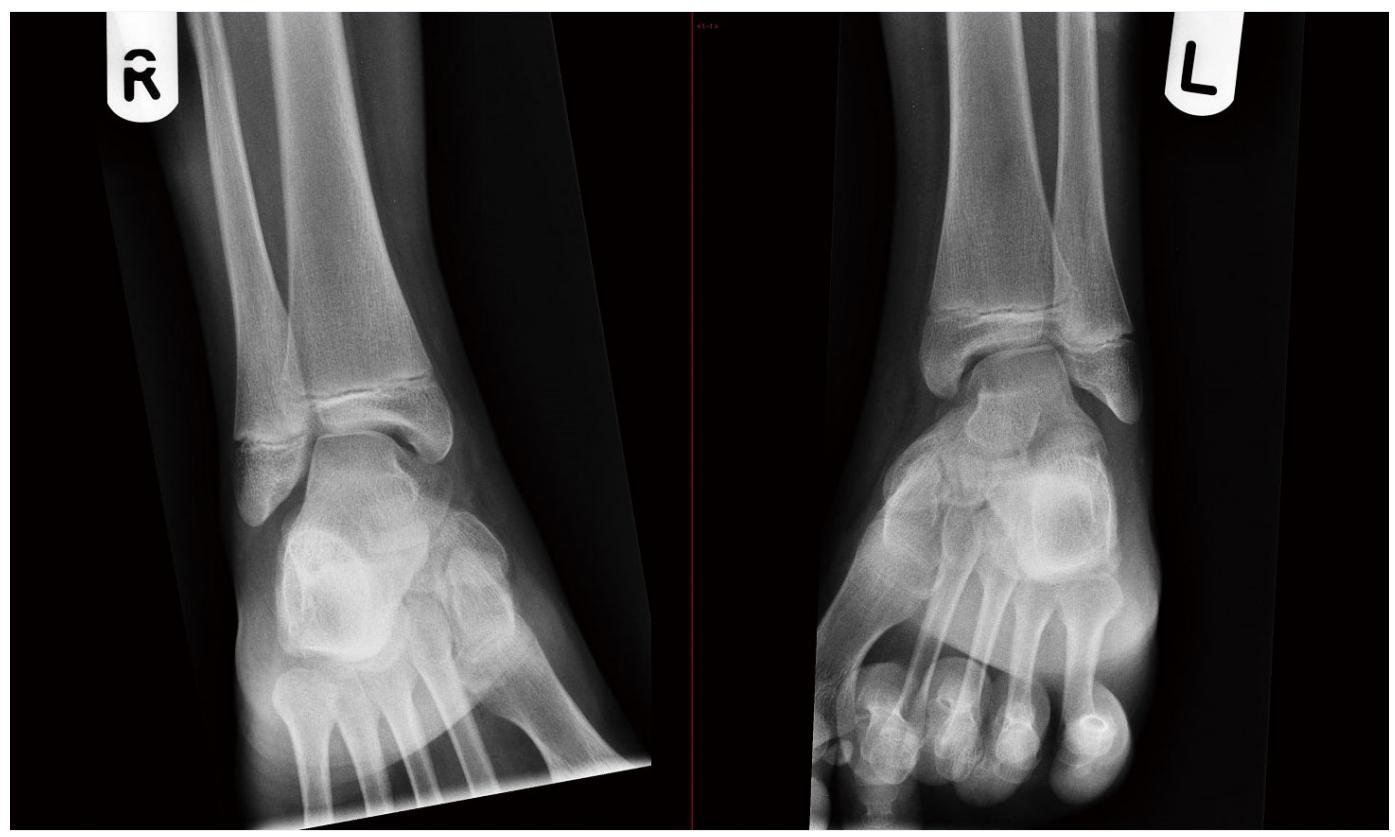

Figure 5. AP view radiographs of both ankles of the child demonstrating bilateral ball and socket joints

On review of literature, there are a few published case reports describing ball and socket ankle joint but none of them have described bilateral occurrence and three cases in the same family. In our case series, we found bilateral ball and socket ankle joints in grandmother, mother and son supporting a congenital theory but there was no associated congenital abnormality, which makes it different from the other published case reports. In this scenario, we believe this condition has a congenital inheritance supported by three cases with bilateral occurrence in the same family.

In this case the condition was not diagnosed on initial radiographs or MRI scans, but was diagnosed after a few months

\section{REFERENCES}

[1] Takakura Y, Tamai S, Masuhara K. Genesis of the ball-and-socket ankle. The Journal of Bone and Joint Surgery British Volume. 1986; 68(5): 834-837. PMid:3782257

[2] Schreiber RR. Congenital and Acquired Ball-And-Socket Ankle Joint. Radiology. 1965; 84: 940-944. PMid:14282708 https ://doi .or g/10.1148/84.5.940

[3] Pistoia f, Ozonoff MB, Wintz P. Ball and Socket ankle joint. Skeletal Published by Sciedu Press later. Therefore, we think it is important for clinicians and radiologists to be aware of the possibility of a ball and socket ankle joint in a patient with ankle pain.

\section{Informed consent}

Informed consent was obtained from all individual participants included in the study.

\section{Disclosure}

The authors declare that they have no conflict of interest.

\section{CONFLICTS OF INTEREST Disclosure}

There are no financial associations to declare.
Radiology. 1987; 16(6): 447-51. PMid:3659990 https://doi.or $\mathrm{g} / 10.1007 / \mathrm{BF} 00350538$

[4] Cetinus E, Uzel M, Bilgic E, et al. A case of ball and socket deformity of the ankle joint. Acta Orthop Traumatol Turc. 2003; 37(5): 406-9. PMid: 14963398

[5] Harris EJ. Short limb and the ball and socket ankle deformity, J Am Podiatr Med Assoc. 1989; 79(12): 595-604. PMid:2696785 https://doi.org/10.7547/87507315-79-12-595 
[6] Ruiz Santiago F, Picazo Moreno C, Canadillas Barea L, et al. Balland-socket ankle joint with hypoplastic sustentaculum tali. European Radiology. 2002; 12 Suppl 3: S48-50. PMid:12522602
[7] Lewis JS Jr, De Orio JK. The adult ball-and-socket ankle joint: surgical management of late ankle and subtalar arthritis. Foot Ankle Spec. 2015; 8(2): 112-8. PMid:25205679 https://doi .org/10.1177/ 1938640014548321 